\title{
Modulation of biomarkers related to tumor initiation and promotion in mouse skin by a natural $\beta$-glucuronidase inhibitor and its precursors
}

\author{
MAGDALENA C. KOWALCZYK ${ }^{1}$, ERICK SPEARS ${ }^{4}$, MACIEJ NAROG $^{5}$, ROBERT ZOLTASZEK $^{1}$, \\ PIOTR KOWALCZYK ${ }^{1}$, MARGARET HANAUSEK ${ }^{1}$, NAOKI YOSHIMI ${ }^{6}$, \\ THOMAS J. SLAGA ${ }^{1-3}$ and ZBIGNIEW WALASZEK ${ }^{1}$
}

\begin{abstract}
${ }^{1}$ Department of Pharmacology, ${ }^{2}$ The Cancer Therapy and Research Center, ${ }^{3}$ Medical Research Division of the Regional Academic Health Center, University of Texas Health Science Center at San Antonio, San Antonio, TX 78229; ${ }^{4}$ Department of Molecular Bioscience, University of Kansas, 2034 Haworth Hall, Lawrence, KS 66045; ${ }^{5}$ AMC Cancer Research Center, Denver, CO 80214, USA; ${ }^{6}$ Department of Pathology and Oncology, Graduate School of Medicine and Faculty of Medicine, University of the Ryukyus, Okinawa 903-0214, Japan
\end{abstract}

Received April 4, 2011; Accepted April 26, 2011

DOI: $10.3892 / o r .2011 .1351$

\begin{abstract}
Carcinogen-mediated labilization of lysosomal enzymes such as $\beta$-glucuronidase $(\beta G)$ is often associated with the general process of inflammation. Therefore, the primary goal of this study was to demonstrate that exposing the skin of SENCAR mice to the natural $\beta \mathrm{G}$ inhibitor D-glucaro-1,4-lactone (1,4-GL) and its precursor D-glucuronic acid- $\gamma$-lactone (GUL), prior to and during 7,12-dimethylbenz $[\alpha]$ anthracene (DMBA) treatment inhibits not only epidermal hyperplasia but also inflammation in the mouse skin complete carcinogenesis model, i.e., the 4-week inflammatory-hyperplasia assay. Topical administration of $1,4-\mathrm{GL}$ or GUL prior to repetitive, high-dose DMBA treatment markedly and in a doserelated manner inhibited DMBA-induced epidermal hyperplasia (i.e., up to 57\%). DMBA-mediated Ha-ras mutations in codon 61 were reduced by up to $78 \%$ by $1,4-$ GL. DMBAinduced inflammation, as measured by dermal leukocyte counts and immunologically, was inhibited by up to $37 \%$ by topical 1,4-GL but not by GUL. The inhibition of cellular proliferation and inflammation coincided with the inhibition of $\beta G$ expression. Thus, the present study suggests that in the DMBA-induced complete skin carcinogenesis model, 1,4-GL when applied topically had both anti-proliferative properties as well as anti-inflammatory properties, whereas GUL had only anti-proliferative when applied topically. However, the number of inflammatory cells in the dermal portion of the
\end{abstract}

Correspondence to: Dr Magdalena C. Kowalczyk, Department of Pharmacology, University of Texas Health Science Center at San Antonio, 7703 Floyd Curl Drive, San Antonio, TX 78229, USA

E-mail: magdagorka@hotmail.com

Key words: skin, SENCAR mice, carcinogenesis, prevention, $\beta$-glucuronidase inhibitors skin of mice was significantly reduced by dietary treatment of GUL, whereas both topical and dietary treatments with 1,4-GL were very effective.

\section{Introduction}

We have previously shown (1-3) that the natural $\beta$-glucuronidase $(\beta \mathrm{G})$ inhibitor D-glucaro-1,4-lactone (1,4-GL) and its synthetic precursors, such as 2,5-di-O-acetyl-D-1,4-glucaro-6,3-dilactone (DADGL) detoxify chemical carcinogens that undergo glucuronidation and inhibit chemically-induced experimental tumorigenesis, in part, by inhibiting the enzyme $\beta \mathrm{G}$ and by suppressing cell proliferation. DADGL (aceglatone) is more stable than 1,4-GL and is used in Japan as a post-operative cancer prophylactic agent. We previously (4) demonstrated that exposing the skin of SENCAR mice to a natural and to synthetic $\beta$ Ginhibitors prior to and during 7,12-dimethylbenz $[\alpha]$ anthracene (DMBA) treatment selectively inhibited intermediate end-point biomarkers in the DMBA-induced mouse skin complete carcinogenesis model, i.e., the 4-week inflammatoryhyperplasia assay. We have also shown that $\beta \mathrm{G}$ inhibition suppressed the formation of DMBA-initiated, 12-O-tetradecanoylphorbol-13-acetate (TPA)-promoted skin tumors in SENCAR mice. Topical administration of 1,4-GL or DADGL prior to repetitive, high-dose DMBA treatment markedly and in a dose-related manner inhibited DMBA-induced epidermal hyperplasia (i.e., up to $69 \%$ ). DMBA-induced ornithine decarboxylase (ODC) expression was inhibited by up to 44 and $68 \%$ in the interfollicular and perifollicural epidermis, respectively. The inhibition of ODC expression coincided with the inhibition of $\beta \mathrm{G}$ expression. There were no statistically significant differences in the effectiveness of topical 1,4-GL and DADGL. 1,4-GL inhibited in a dose-dependent fashion inhibited the TPA-induced epidermal ODC activity in mice. It also reduced the DNA-labeling index and the mitotic index of epidermal cells. Topical application of 1,4-GL prior to treatment 
with DMBA or TPA significantly suppressed the formation of papillomas in SENCAR mice (initiation/promotion model). These results suggest that topical 1,4-GL or DADGL may exert their chemopreventive action during chemically induced mouse skin tumorigenesis, in part, through $\beta G$-mediated detoxification and through alterations in the ODC expression and cell proliferation in the target organ (4).

Recently, Morita et al (3), investigated the chemopreventive effects of DADGL and D-glucuronic acid- $\gamma$-lactone (GUL), i.e., the synthetic and natural precursors of a 1,4-GL, respectively, on azoxymethane (AOM)-induced rat colon carcinogenesis. The results of that study show the inhibitory effects of DADGL and GUL on the initiation and post-initiation phases of AOM-induced colon carcinogenesis in rats. Morita et al (3), concluded that as precursors of the ultimate $\beta$-glucuronidase inhibitor, i.e., 1,4-GL, DADGL and GUL might exert their chemopreventive action through multiple mechanisms, such as inhibition of $\beta$-glucuronidase, reduction of cell proliferation and induction of apoptosis.

The primary goal of the present study was to demonstrate that exposing the skin of SENCAR mice to the endogenous $\beta G$ inhibitor, i.e., 1,4-GL and its natural precursor i.e., GUL, prior to and during DMBA treatment inhibits not only epidermal hyperplasia but selected biomarkers of inflammation in the DMBA-induced mouse skin complete carcinogenesis model, i.e., the 4-week inflammatory-hyperplasia assay.

\section{Materials and methods}

Tested compounds and chemicals. All tested compounds as well as other chemicals used in this study were obtained from Sigma-Aldrich (St. Louis, MO), and were of analytical grade or of the highest grade available. DMBA, used as the complete carcinogen for appropriate control and experimental groups, was also obtained from Sigma-Aldrich; dosing solution was prepared using high-purity acetone, and was subjected to concentration analysis prior to use.

Animals. Female SENCAR mice, 5-6-week old, were purchased from the National Cancer Institute, Frederick Cancer Research and Development Center (Frederick, MD), and placed into quarantine for one week prior to beginning carcinogen treatment. Mice were housed in groups of five under conditions of constant temperature and humidity and maintained on a 12-h light/dark cycle with ad libitum access to food and water. All animal procedures were performed in accordance with the National Institutes of Health Guidelines, and were approved by the Institutional Animal Care and Use Committee.

Induction of epidermal hyperplasia and dermal inflammation. At 6-7 weeks of age the backs of mice were shaved. The DMBA solution was prepared under yellow light immediately before use. The dose of $100 \mathrm{nmol}(25 \mu \mathrm{g})$ DMBA dissolved in acetone $(200 \mu \mathrm{l})$ was applied twice weekly and the selected inhibitors were applied in a total volume of $200 \mu \mathrm{l}$ of acetone, either topically $20 \mathrm{~min}$ prior to DMBA or were given continually in the diet, beginning 2 weeks prior to the first dose of DMBA. The test compounds and DMBA were given twice a week for 4 weeks. Two days after the last treatment, mice were sacrificed and skin samples were collected for immunostaining and DNA isolations. For dietary treatments 0.5 and $1 \%$ of $1,4-\mathrm{GL}$ or 1 and $5 \%$ of GUL were administered in the AIN-93G diet (Dyets Inc., Bethlehem, PA). For topical administration of 1,4-GL, GUL and D-glucono-1,5-lactone (GOL) (non- $\beta \mathrm{G}$ inhibitor control), the concentrations between $0.5-4 \mathrm{mg}$ in $200 \mu \mathrm{l}$ acetone were used.

Tissue preparation. Mice were sacrificed by carbon dioxide suffocation and skin samples were collected from the dosed area of each animal. Sections specified for histological evaluation were fixed in $10 \%$ neutral-buffered formalin overnight and transferred to $70 \%$ ethanol the next day for paraffin embedment using standard procedures. Skin sections (5 $\mu \mathrm{m})$ were cut on a microtome and mounted on polylysinetreated glass slides until processing for immunohistochemistry. Two thirds of the dorsal skin tissues were frozen using liquid nitrogen for DNA isolation.

$\beta$-glucuronidase activity. The $\beta \mathrm{G}$ activity in mouse dermis and epidermis was assayed by a colorimetric procedure as described in the literature (5).

Histological evaluation. The tissues were prepared for histological evaluation by using conventional paraffin sections and hematoxylin-eosin staining. Approximately $1 \mathrm{~cm}^{2}$ of each skin sample was preserved in formalin for immunohistochemistry. Epithelial thickness was determined, using an Olympus microscope B45 (Olympus Corp., Leeds Instruments, Inc., Irving, TX), from at least 20 randomly selected sites in formalin-fixed skin samples. Total dermal cellularity as a measure of inflammation was evaluated in a minimum of 10 random dermal fields of each animal. Interleukin-1 $\alpha$ (IL-1 $\alpha$ ) expression was evaluated using IL- $1 \alpha(\mathrm{H}-159)$ antibody. This rabbit polyclonal antibody was raised against recombinant protein corresponding to amino acids 113-271 representing mature IL- $1 \alpha$ of human origin. The antibody was obtained from Santa Cruz Biotechnology, Inc. (Santa Cruz, CA). The $90 \mathrm{kDa}$ heat shock protein (Hsp90) was detected immunohistochemically using mouse monoclonal (S88) antibody raised to Hsp90 protein. The antibody was obtained from Abcam, Inc. (Cambridge, MA).

Restriction analysis of Ha-ras mutations in codon 61. Detection of $\mathrm{CAA} \rightarrow \mathrm{CTA}$ transversion in codon 61 of the Ha-ras gene was performed by PCR amplification on DNA obtained from paraffin-embedded tissue as described by Bianchi et al (6). The reactions were performed using two different sets of primers: the first was able to amplify only wild-type of Ha-ras and the second, was capable of amplifying only the mutated DNA (7). The following primers were used: forward primer for both wild-type and mutant Ha-ras, 5'-CTAAGCCTGTTG TTTTGCAGGAC-3'; reverse primer for wild-type Ha-ras, 5'-CATGGCACTATACTCTTCTT-3'; reverse primer for mutant Ha-ras, 5'-CATGGCACTATACTCTTCTA-3'. PCR was performed at $94^{\circ} \mathrm{C}$ for $2 \mathrm{~min}$ followed by 30 cycles of $94^{\circ} \mathrm{C}, 57^{\circ} \mathrm{C}$ and $72^{\circ} \mathrm{C}$ for $30 \mathrm{sec}$ each. PCR products were radioactively labeled by incorporation of dCTP containing ${ }^{32} \mathrm{P}$ and visualized by polyacrylamide gel electrophoresis and autoradiography. Band intensities for both mutant and wildtype reactions were quantified by Kodak Digital Science ${ }^{\mathrm{TM}}$ 

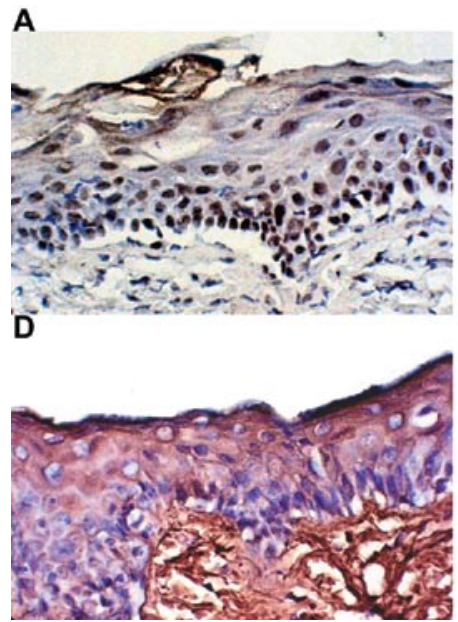

B

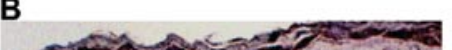

C

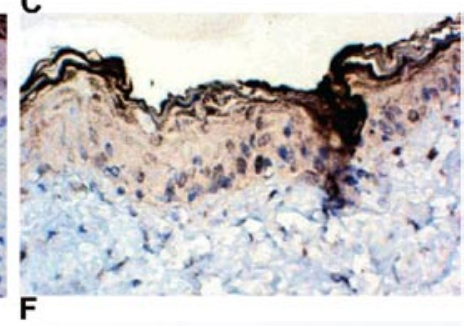

E
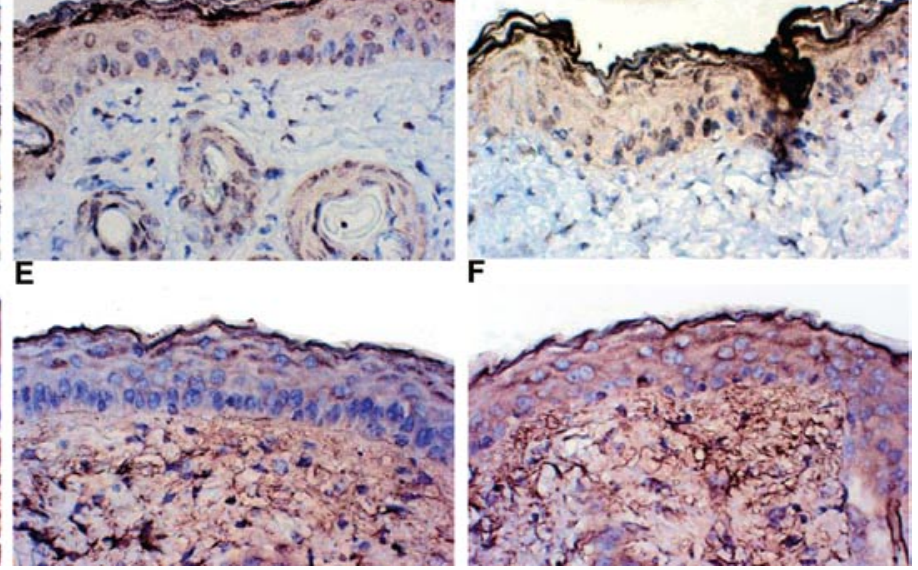

Figure 1. Representative microphotographs of SENCAR mice skin sections obtained from experimental mice in the complete carcinogenesis experiment after a 4-week treatment with (A and D) DMBA (100 nmol, twice a week), (B and E) 1,4-GL/DMBA (4 mg of 1,4-GL followed by 100 nmol of DMBA, twice a week), and (C and F) GUL/DMBA (4 mg of GUL followed by $100 \mathrm{nmol}$ of DMBA, twice a week). Immunostaining was carried out with an anti-IL-1 $\alpha$ (A-C) and anti-Hsp90 (D-F) antibody.

1D Image Analysis software. Mutant band intensity was expressed as a percentage of wild-type band intensity for each sample in order to numerically express the presence or absence of mutation.

Modified DNA bases: 8-hydroxy-2'-deoxyguanosine (8-OH$d G)$ analysis. The $8-\mathrm{OH}-\mathrm{dG}$ in treated skin was quantified using the isocratic high-pressure liquid chromatography (HPLC) method of McCabe et al (8) as described by Hanausek et al (9). Approximately 100-200 $\mu \mathrm{g}$ of DNA from each sample was hydrolyzed to individual nucleosides with nuclease P1 and alkaline phosphatase and injected on a column. The mobile phase was $100 \mathrm{mM}$ sodium acetate in $4 \%$ methanol, $\mathrm{pH}$ 5.2. All reagents were HPLC grade and mili-Q water was further purified using a Waters Sep-Pak solid phase extraction column. Isocratic analysis took place on a Shimadzu LC-600 pump connected to a Spectra system AS3500 autosampler. An YMC basic S3, 4.6x150 mm column was used for separation. The oxidized guanine adduct, $8-\mathrm{OH}-\mathrm{dG}$, was detected using a CoulArray electrochemical detection system (ESA, Inc., Chelmsford, MA) as described earlier (9). Sample adduct concentrations were calculated from standard curves of $8-\mathrm{OH}-$ dG, 0.1-1.5 pmol, and 2'-deoxyguanosine (dG), 0.5-15.0 nmol. All data were analyzed using ESA CoulArray for Windows software and expressed in terms of the ratio of picomoles $8-\mathrm{OH}-\mathrm{dG} / 10^{5}$ picomoles $\mathrm{dG}(8)$.

Statistical analysis. The results are expressed as means \pm SD. For comparison of the differences between the groups a two-tailed, unpaired, Student's t-test was used. A P-value $<0.05$ was considered statistically significant.

\section{Results}

Effects of compounds on sustained epidermal hyperplasia. The induction of epidermal hyperplasia by DMBA and its inhibition after multiple treatments with each tested compound is summarized in Fig. 1 and Table I. The results are the averages of 20 measurements at various randomly selected locations along the epidermis of the skin specimen from each treatment group. DMBA alone increased epidermal thickness 5 times from on average $12.4 \pm 0.9 \mu \mathrm{m}$ in normal mouse skin to $66.1 \pm 12.4 \mu \mathrm{m}$ in DMBA treated skin. Both, 1,4-GL as well as GUL inhibited hyperplasia in a dose-dependent manner. Both ways of application (dietary and topical treatment) showed statistically significant $(\mathrm{P}<0.05)$ inhibitory effects on DMBAinduced hyperplasia (except topical GUL at the lowest dose). The most potent inhibition was observed in the group of mice treated with 1,4-GL which reduced the DMBA-induced epidermal thickness by $95 \%$ at the $4 \mathrm{mg}$ topical dose. A dose of $4 \mathrm{mg}$ GOL, which we used as a non- $\beta \mathrm{G}$ inhibitor control had no effect, i.e., it did not decrease DMBA-induced epidermal thickness.

Effect of inhibitors on dermal leukocyte counts and on IL-1 $\alpha$ and Hsp90 expression in mouse skin treated with DMBA. The hyperplasia in DMBA-treated skin was associated with higher levels of IL-1 $\alpha$ and Hsp90 expression; these enzymes are associated with inflammation and tumorigenesis. Epithelia treated with DMBA had increased levels of these enzymes (Fig. 1). The microphotographs of representative skin specimens showed that both 1.4-GL and GUL markedly reduced IL-1 $\alpha$ and Hsp90 expression as compared to positive control (DMBA). Also dermal leukocyte counts (Table I) were reduced by the inhibitors but the reductions were not always statistically significant.

Effect of 1,4-GL on $\beta$-glucuronidase activity. Elevated levels of $\beta \mathrm{G}$ activity are associated with an increased risk of various cancers. In inflammation, $\beta \mathrm{G}$ is known to be released from granulocytes including neutrophils (10), and to be a potential biomarker useful in the monitoring of pulmonary inflammation caused by human exposure to tobacco smoke and other environmental agents. $\beta \mathrm{G}$ inhibitors, such as $1,4-\mathrm{GL}$ and its precursors, exert a preventive action on breast, prostate, colon, lung and skin carcinogenesis (reviewed by Walaszek) (1). The $\beta \mathrm{G}$ activity in dermis and epidermis after treatment with 1,4-GL is shown in Fig. 2. Time-course of $\beta \mathrm{G}$ inhibition by 
Table I. Effects of topical or dietary administration of 1,4-GL, GUL and GOL on epidermal thickness and inflammatory response in the dermis of DMBA-treated female SENCAR mice.

\begin{tabular}{|c|c|c|}
\hline Experimental group & Epidermal thickness $(\mu \mathrm{m})^{\mathrm{a}}$ & Inflammatory response ${ }^{\mathrm{b}}$ \\
\hline \multicolumn{3}{|l|}{ Topical treatment } \\
\hline None/acetone & $12.4 \pm 0.9$ & $5.9 \pm 0.7$ \\
\hline None/DMBA & $66.1 \pm 12.4$ & $21.6 \pm 2.4$ \\
\hline $4 \mathrm{mg} \mathrm{1,4-GL/acetone}$ & $15.0 \pm 1.2^{\mathrm{c}}$ & $5.0 \pm 1.2^{\mathrm{c}}$ \\
\hline $0.5 \mathrm{mg} 1,4-\mathrm{GL} / \mathrm{DMBA}$ & $47.3 \pm 2.6^{c}$ & $17.3 \pm 2.6$ \\
\hline $2 \mathrm{mg} \mathrm{1,4-GL/DMBA}$ & $35.2 \pm 1.6^{c}$ & $15.2 \pm 1.6^{\mathrm{c}}$ \\
\hline $4 \mathrm{mg} \mathrm{1,4-GL/DMBA}$ & $28.7 \pm 5.3^{c}$ & $13.7 \pm 1.3^{\mathrm{c}}$ \\
\hline 4 mg GUL/acetone & $15.8 \pm 3.7^{c}$ & $5.2 \pm 07^{c}$ \\
\hline $0.5 \mathrm{mg}$ GUL/DMBA & $59.5 \pm 1.9$ & $19.5 \pm 1.9$ \\
\hline 2 mg GUL/DMBA & $43.7 \pm 2.0^{c}$ & $19.7 \pm 2.0$ \\
\hline 4 mg GUL/DMBA & $33.6 \pm 1.9^{c}$ & $20.6 \pm 1.9$ \\
\hline 4 mg GOL/DMBA & $62.4 \pm 1.4$ & $22.1 \pm 1.4$ \\
\hline \multicolumn{3}{|l|}{ Dietary treatment } \\
\hline $0.5 \% 1,4-G L / D M B A$ & $36.6 \pm 7.0^{c}$ & $16.6 \pm 2.0^{c}$ \\
\hline $1 \%$ 1,4-GL/DMBA & $31.2 \pm 4.5^{\mathrm{c}}$ & $14.2 \pm 1.6^{\mathrm{c}}$ \\
\hline $1 \%$ GUL/DMBA & $39.9 \pm 7.7^{\mathrm{c}}$ & $19.9 \pm 1.7$ \\
\hline $5 \%$ GUL/DMBA & $27.2 \pm 4.3^{\mathrm{c}}$ & $17.1 \pm 1.3^{\mathrm{c}}$ \\
\hline
\end{tabular}

The results are the averages of 20 measurements at various locations along the epidermis of the skin specimens from each treatment group.

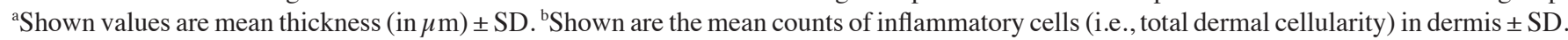
${ }^{\mathrm{c}}$ Statistically different from controls $(\mathrm{P}<0.05)$. Group size $\mathrm{n}=5$.
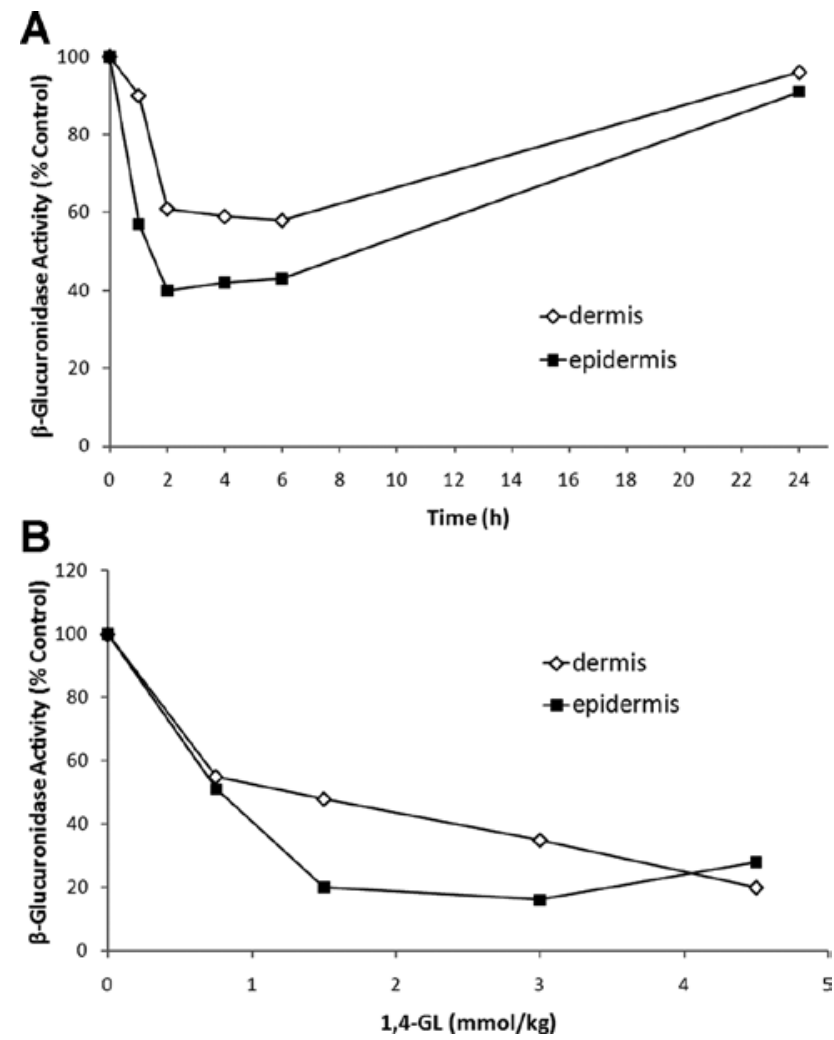

Figure 2. Time-course curves of dermal and epidermal $\beta$-glucuronidase activity (A) following the administration of $1 \mathrm{mmol} / \mathrm{kg}$ of the inhibitor 1,4 $\mathrm{GL}$, and dose-response curves for 1,4-GL inhibition of dermal and epidermal $\beta$-glucuronidase (B). The enzyme activity was reduced by $60 \%$ at $\sim 1 \mathrm{mmol} / \mathrm{kg}$ body weight and by $80 \%$ at $1.5-3 \mathrm{mmol} / \mathrm{kg}$ body weight.
$1 \mathrm{mmol} / \mathrm{kg}$ dose of $1,4-\mathrm{GL}$ in dermis and epidermis is shown in Fig. 2A. It was also found that 1,4-GL inhibits $\beta$ G activity in a dose-dependent manner (Fig. 2B).

Analysis of mutations in codon 61 of Ha-ras oncogene in skin of SENCAR mice. After initiation with DMBA in vivo, the majority of the papillomas that appear have an $\mathrm{A} \rightarrow \mathrm{T}$ mutation in the second position of codon 61 of the Ha-ras oncogene (11). This transversion in ras oncogene is presumed to be an initiating event, triggering multiple signaling cascades, distortion of the cellular balance between proliferation and apoptosis, eventually leading to progression of ras-initiated cells to malignancy $(9,12)$. The mutation can be detected very early after the initiating treatment. Ha-ras mutation in codon 61 in the DMBA-treated skin was analyzed using a polymerase chain reaction protocol derived from Nelson et al (7). The mutant and wild-type genes were amplified with mutation specific primers and analyzed by polyacrylamide gel electrophoresis. Amplification products were radioactively labeled with ${ }^{32} \mathrm{P}$. The band intensity for both mutant and wild-type reactions was quantified using Kodak Digital Science 1D Image Analysis software. The mutant band intensity was expressed as a percentage of the wild-type band intensity for each sample. Both dietary and topical 1,4-GL significantly inhibited the mutation of the Ha-ras oncogene. Examples of autoradiography results of the Ha-ras analysis using the mismatch specific primers are shown in Fig. 3. Both, the wildtype and mutant primer PCR analyses were conducted in parallel for the same sample. With amplification conditions 


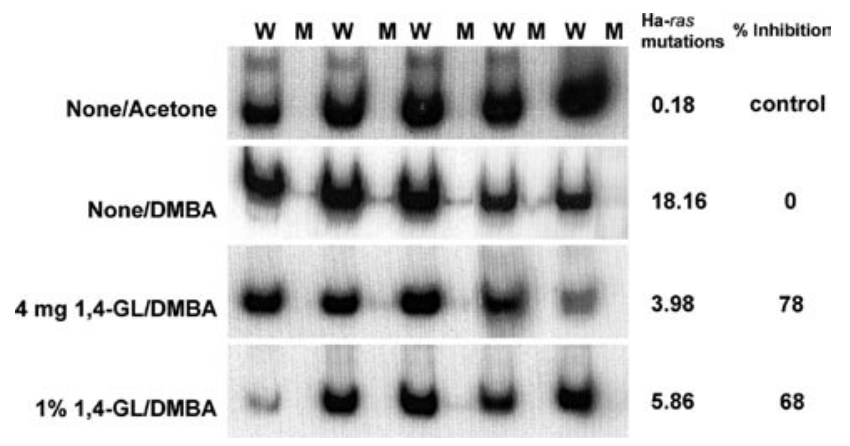

Figure 3. PCR analysis of the effect of topical and dietary treatment with 1,4-GL on Ha-ras mutation in codon 61 induced in mouse skin by DMBA. The wild-type (W) and mutant (M) genes were amplified with mutationspecific primers and analyzed by polyacrylamide gel electrophoresis. Mutant band intensity was expressed as a percentage of wild-type band intensity for each sample. Group size $n=5$.

identical and within the linear range of the amplification curve for both the mutant and wild-type PCR reactions, mutant and wild-type signals were directly compared $(7,13)$.

8-Hydroxy-2'-deoxyguanosine. Oxygen free radical attack on DNA may lead to strand breakage and/or formation of modified bases like thymine glycol, hydroxyl-methyl-uracil, or 8-OH-dG. Oxygen free radical damage to DNA may be repaired depending on the type and extent of the damage, but little is known regarding the repair of $8-\mathrm{OH}-\mathrm{dG}$ in vivo $(8,14,15)$. DMBA produced statistically significant increases in 8-OH-dG levels compared to control animals, while 1,4-GL and GUL treatment (dietary as well topical treatments), gave a statistically significant decrease in the $8-\mathrm{OH}-\mathrm{dG}$ to $10^{5} \mathrm{dG}$ ratio in the complete carcinogenesis protocol (Fig. 4).

\section{Discussion}

In both rat and human liver and in mouse and human skin, D-glucurono- $\gamma$-lactone dehydrogenases have been found responsible (5) for oxidation of the D-glucurono- $\gamma$-lactone to an immediate precursor of 1,4-GL. However, a free radical mechanism of the oxidation of GUL has also been suggested (16). Our goal was to compare the effect of 1,4-GL and its natural precursor GUL on early events in DMBA-induced skin tumorigenesis in SENCAR mice. It has been shown that 1,4-GL inhibits $\beta \mathrm{G}$ and enhances phase II detoxification (17). Some in vitro and animal data suggest that inhibition of $\beta G$ may suppress carcinogenesis (2) by inhibiting the initiation and promotion/progression stages of tumorigenesis (18-20).

It is well known that a variety of chemical and physical agents can cause skin cancer in rodents and man. Treatment with a well-known skin carcinogen DMBA at the appropriate dosage and frequency of application, leads to inflammation, regenerative hyperplasia, dysplasia, papillomas and finally squamous cell carcinomas (21). DMBA, when applied topically to mouse skin at a carcinogenic dose of $100 \mathrm{nmol}$ twice weekly for at least 4 weeks, has both initiating and promoting activities. For this reason, DMBA is known as a complete carcinogen, since a separate chemical promoter is not required $(21,22)$.

Topical application of $100 \mathrm{nmol}$ DMBA twice weekly for 4 weeks resulted in epidermal hyperplasia manifested as

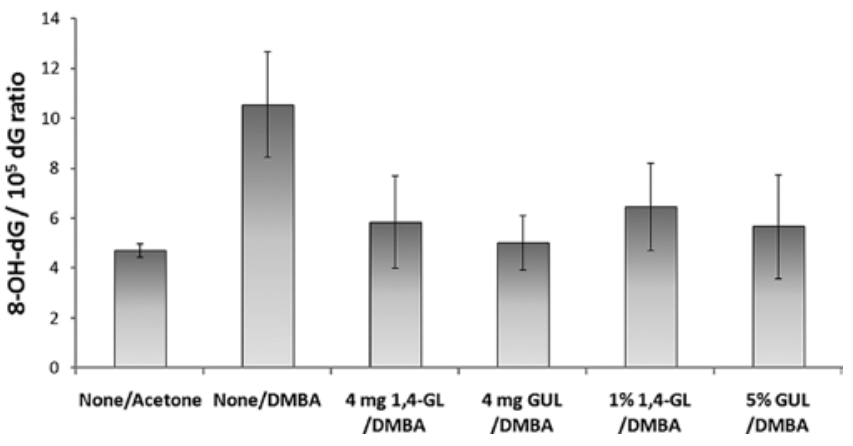

Figure 4. Ratios (pmpl/pmol) of 8-Hydroxy-2'-deoxyguanosine/10 2 '-deoxyguanosine for epidermal tissue samples ( $\mathrm{n}=5$ per group) obtained from SENCAR mice treated with 1,4-GL and GUL (both topically and dietary). Differences between the DMBA group and all other groups are statistically significant $(\mathrm{P} \leq 0.05)$

enhanced thickness due to an increase in cellularity up to 10 cell layers. The hyperplasia in the mouse skin was associated with increased expression of the inflammation markers IL-1 $\alpha$ and heat shock protein Hsp90 in the skin of DMBA-treated mice compared to untreated controls. Topical administration of 1,4-GL or GUL prior to repetitive, high-dose DMBA treatment markedly and in a dose-related manner inhibited DMBA-induced epidermal hyperplasia (i.e., up to 57\%).

It has been reported that the levels of proinflammatory cytokines, such as IL-1 and C-reactive protein, circulating markers of inflammation, correlated well with $\beta \mathrm{G}$ activity in serum from patients with inflammatory disorders (23). The inflammatory microenvironment is thought to play a pivotal role in tumorigenesis. Evidence suggests that proinflammatory cytokines in the tumor microenvironment play a critical part in this process. Cytokines are released in response to a diverse range of cellular stresses, such as infection and inflammation, including a response to carcinogens (24-26). Interleukins are particularly important biomolecules that regulate inflammatory and immune responses. Proinflammatory cytokines are abundant in the microenvironment of various tumors, and cytokines such as TNF $\alpha$ promote the transformation of precancerous cells to malignant ones (26). Proinflammatory cytokines are also thought to affect later stages of tumor progression, including angiogenesis and metastasis. The longer the inflammation persists, the higher the risk of associated carcinogenesis.

In our studies, the number of inflammatory cells in the dermal portion of the skin of mice measured by dermal leukocyte counts and immunologically was significantly reduced by both topical and dietary 1,4-GL treatments, while only dietary GUL reduced these biomarkers of inflammation. The inhibition of cellular proliferation and inflammation coincided with the inhibition of $\beta G$ expression.

Although numerous oxidative DNA lesions may result from DMBA treatment, the presence of elevated 8-OH-dG has been linked to the development of cancer $(14,27)$. DMBAmediated oxidative damage, i.e., hydroxylation of 2'-dG was inhibited by topical and dietary administration of the test compounds; in case of topical treatment with GUL, the DMBA-induced oxidative damage was minimal, i.e., close to the negative control level. The treatment of 1,4-GL was also 
very effective in inhibiting Ha-ras mutations showing very strong anti-initiation effects, i.e., reducing mutations in codon 61 by up to $78 \%$.

In conclusion, the present study suggests that in the DMBA-induced complete skin carcinogenesis model, 1,4-GL and its precursor GUL have antiproliferative properties as well as anti-inflammatory properties. We have found that both 1,4-GL and its precursor GUL showed dose-dependent effects, and especially at higher doses reduced hyperplasia and modulated expression of selected inflammation markers.

\section{Acknowledgements}

The present study was supported by NIH grants R01 CA 102747 and P30 CA 54174-1651.

\section{References}

1. Walaszek Z: Potential use of D-glucaric acid derivatives in cancer prevention. Cancer Lett 54: 1-8, 1990.

2. Yoshimi N, Walaszek Z, Mori H, Hanausek M, Szemraj J and Slaga TJ: Inhibition of azoxymethane-induced rat colon carcinogenesis by potassium hydrogen D-glucarate. Int J Oncol 16: 43-48, 2000.

3. Morita N, Walaszek Z, Kinjo T, Nishimaki T, Hanausek M, Slaga TJ, Mori H and Yoshimi N: Effects of synthetic and natural in vivo inhibitors of $\beta$-glucuronidase on azoxymethaneinduced colon carcinogenesis in rats. Mol Med Rep 1: 741-746, 2008.

4. Walaszek Z, Yoshimi N, Hanausek M, Zoltaszek R and Slaga TJ: Modulation of biomarkers and prevention of mouse tumors by natural and synthetic beta-glucuronidase inhibitors. Proc Am Assoc Cancer Res 44: 204, 2003.

5. Levvy GA and Conchie J: $\beta$-glucuronidase and the hydrolysis of glucuronides. In: Glucuronic Acid. Dutton GJ (ed). Academic Press, New York, pp301-364, 1966.

6. Bianchi AB, Navone NM and Conti CJ: Detection of loss of heterozygosity in formalin-fixed paraffin-embedded tumor specimens by the polymerase chain reaction. Am J Pathol 138: 279-284, 1991

7. Nelson MA, Futscher BW, Kinsella T, Wymer J and Bowden GT: Detection of mutant Ha-ras genes in chemically initiated mouse skin epidermis before the development of benign tumors. Proc Natl Acad Sci USA 89: 6398-6402, 1992.

8. McCabe DR, Hensley K and Acworth IN: Method for the detection of nucleosides, bases, and hydroxylated adducts using gradient HPLC with coulometric array and ultraviolet detection. J Med Food 2: 209-214, 1999.

9. Hanausek M, Ganesh P, Walaszek Z, Arntzen CJ, Slaga TJ and Gutterman JU: Avicins, a family of triterpenoid saponins from Acacia victoriae (Bentham), suppress H-ras mutations and aneuploidy in a murine skin carcinogenesis model. Proc Natl Acad Sci USA 98: 11551-11556, 2001.
10. Marshall T, Shult P and Busse WW: Release of lysosomal enzyme beta-glucuronidase from isolated human eosinophils. J Allergy Clin Immunol 82: 550-555, 1988.

11. Quintanilla M, Brown K, Ramsden M and Balmain A: Carcinogen-specific mutation and amplification of Ha-ras during mouse skin carcinogenesis. Nature 322: 78-80, 1986.

12. Li N, Chen X, Liao J, et al: Inhibition of 7,12-dimethylbenz[a] anthracene (DMBA)-induced oral carcinogenesis in hamsters by tea and curcumin. Carcinogenesis 23: 1307-1313, 2002.

13. Finch JS, Albino HE and Bowden GT: Quantitation of early clonal expansion of two mutant 61st codon c-Ha-ras alleles in DMBA/ TPA treated mouse skin by nested PCR/RFLP. Carcinogenesis 17: 2551-2557, 1996.

14. Kasai H, Crain PF, Kuchino Y, Nishimura S, Ootsuyama A and Tanooka H: Formation of 8-hydroxyguanine moiety in cellular DNA by agents producing oxygen radicals and evidence for its repair. Carcinogenesis 7: 1849-1851, 1986.

15. Nomoto M, Yamaguchi R, Kawamura M, Kohno K and Kasai H: Analysis of 8-hydroxyguanine in rat kidney genomic DNA after administration of a renal carcinogen, ferric nitrilotriacetate. Carcinogenesis 20: 837-841, 1999.

16. Blumenthal HJ, Lucuta VL and Blumenthal DC: Specific enzymatic assay for D-glucarate in human serum. Anal Biochem 185: 286-293, 1990 .

17. Walaszek Z, Szemraj J, Narog M, et al: Metabolism, uptake, and excretion of a D-glucaric acid salt and its potential use in cancer prevention. Cancer Detect Prev 21: 178-190, 1997.

18. Walaszek Z, Hanausek M and Slaga TJ: Mechanisms of chemoprevention. Chest 125 (Suppl 5): S128-S133, 2004.

19. Hanausek M, Walaszek Z and Slaga TJ: Detoxifying cancer causing agents to prevent cancer. Integr Cancer Ther 2: 139-144, 2003.

20. Abou-Issa H, Moeschberger M, el-Masry W, Tejwani S, Curley RW Jr and Webb TE: Relative efficacy of glucarate on the initiation and promotion phases of rat mammary carcinogenesis. Anticancer Res 15: 805-810, 1995.

21. DiGiovanni J: Multistage carcinogenesis in mouse skin. Pharmacol Ther 54: 63-128, 1992.

22. Dipple A, Moschel RC and Bigger CAH: Polynuclear aromatic carcinogens. In: Chemical Carcinogens. 2nd edition. Searle CE (ed). ACS Monograph 182, American Chemical Society, Washington D.C., pp41-163, 1992.

23. Shimoi K, Saka N, Nozawa R, et al: Deglucuronidation of a flavonoid, luteolin monoglucuronide, during inflammation. Drug Metab Dispos 29: 1521-1524, 2001.

24. Coussens LM and Werb Z: Inflammatory cells and cancer: think different! J Exp Med 193: F23-F26, 2001.

25. Kishimoto T: Interleukin-6: from basic science to medicine - 40 years in immunology. Annu Rev Immunol 23: 1-21, 2005.

26. Wajant H, Pfizenmaier K and Scheurich P: Tumor necrosis factor signaling. Cell Death Differ 10: 45-65, 2003.

27. Floyd RA: Serendipitous findings while researching oxygen free radicals. Free Radic Biol Med 46: 1004-1013, 2009. 